\title{
Surface Interactions and Degradation of a Fluoroquinolone Antibiotic in the Dark in
} Aqueous $\mathrm{TiO}_{2}$ Suspensions

${ }^{a}$ Department of Geological \& Environmental Sciences, Hope College, P.O. Box 9000, Holland, MI 49422-9000, USA

${ }^{\mathrm{b}}$ Environmental Sciences Division, Oak Ridge National Laboratory, P.O. Box 2008, Oak Ridge, TN 37831, USA

${ }^{\mathrm{c}}$ Department of Chemistry, Hope College, P.O. Box 9000, Holland, MI 49422-9000, USA

* $\quad$ Present Address of Corresponding Author:

Jonathan W. Peterson

Department of Geological \& Environmental Sciences

Hope College, P.O. Box 9000

Holland, MI 49422-9000, USA

e-mail: peterson@hope.edu

Tel: +1-(616)-3957133

Fax: +1-(616)-3957125 
40 Abstract

42 Fluoroquinolone antibiotics (FQ) are important drugs used in human and veterinary medicine.

43 Their detection in natural waters and waste water treatment plants, along with increased

44 resistance to FQ among some bacteria, have generated an increased interest in the fate of these

45 drugs in the environment. Partitioning of FQ between an aqueous solution and attendant

46 substrates depends, in part, on the surface reactivity of the adsorbent, commonly a function of

47 particle size, surface charge, and functional groups. This study investigated the surface

48 interactions between the FQ drug ofloxacin (OFL) and titanium oxide $\left(\mathrm{TiO}_{2}\right)$, a common catalyst

49 and widely-observed constituent in many consumer products. Raman and fluorescence

50 spectroscopic techniques, as well as LC/MS, were used to determine the OFL moieties present

51 on $\mathrm{TiO}_{2}$ surfaces and in attendant solutions. Raman spectra indicate that the $\mathrm{C}=\mathrm{O}$ (ketone) group

52 of the quinolone core, the $\mathrm{NH}^{+}$of the piperazinyl ring, and $\mathrm{CH}_{3}$ of benzoxazine core are the most

53 active in sorption onto the $\mathrm{TiO}_{2}$ surface. Raman spectra also show that the sorbed benzoxazine-

54 quinolone core and piperazinyl moieties are readily desorbed from the surface by re-suspending

55 samples in water. Importantly, we found that OFL could be degraded by reacting with $\mathrm{TiO}_{2}$ even

56 in the dark. Complementary LC/MS analysis of the attendant supernatants indicates the presence

57 of de-piperazinylated and de-carboxylated OFL breakdown products in supernatant solutions.

58 Together, both Raman and LC/MS analyses indicate that $\mathrm{TiO}_{2}$ breaks the compound into

59 piperazinyl and carboxylate groups which attach to the surface, whereas de-carboxylated and

60 hydroxylated quinolone moieties remain in solution. The present study thus identifies the

61 sorption mechanisms and breakdown products of $\mathrm{OFL}$ during dark reactions with $\mathrm{TiO}_{2}$, which is

62 critically important for understanding the fate and transport of OFL as it enters the soil and

63 aquatic environment. 


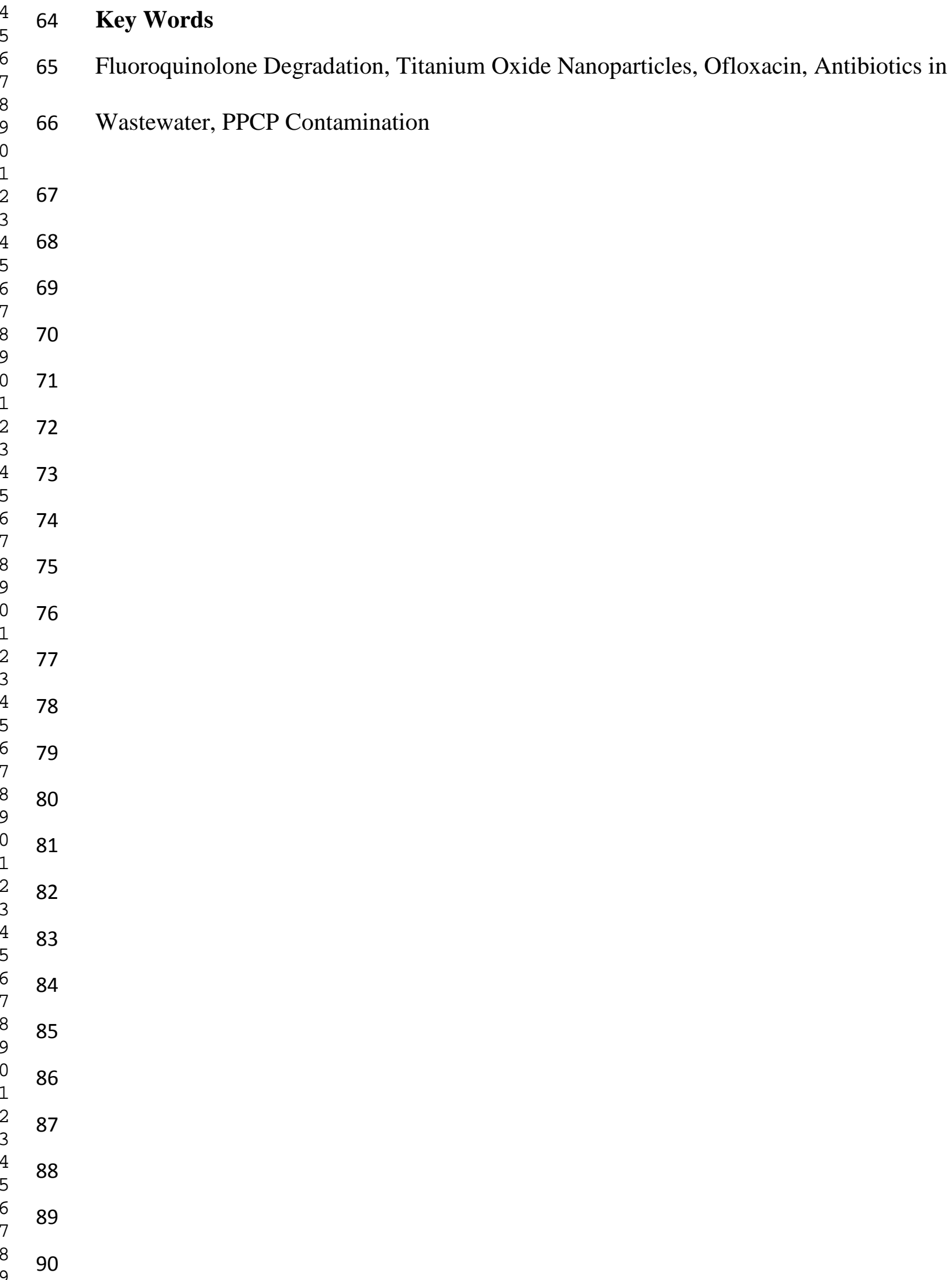


91

92

(

\section{Introduction}

Drugs used in both human and veterinary medicine have been detected in surface water

94 (Zuccato et al., 2000; Kolpin et al., 2002) and ground water (Barnes et al., 2008; Fick et al., 95 2009) in concentrations ranging from $\mathrm{ng} / \mathrm{L}$ to $\mathrm{mg} / \mathrm{L}$. These include antibiotics (Kummerer,

96 2009a,b), as well as their metabolites (Michael et al., 2014), which are a special concern because

97 they can cause antibiotic resistance in certain bacteria. (Normark and Normark, 2002; Giger et

98 al., 2003; Chander et al., 2005; Kim et al., 2007; Yu et al., 2009; Davies and Davies, 2010). This

99 phenomenon is currently considered a major public health threat (CDC, 2013).

101 One group of antibiotics receiving considerable attention is the fluoroquinolones (FQ). Their 102 detection in wastewater treatment plant effluent (Nakata et al., 2005; Vieno et al., 2007), surface 103 waters (Kolpin et al., 2002), ground water (Fick et al., 2009) and soils (Pico and Andreu, 2007) 104 highlights the need to understand the fate and transport of these drugs in natural soil/sediment105 water systems.

107 Fate and transport of FQ in aqueous systems are controlled, in part, by sorption of the 108 compounds to sediment minerals and attendant particles occurring in suspension. Some of the 109 suspended particles will be nanoparticles of rock- forming oxides, including $\mathrm{TiO}_{2}$. $\mathrm{Though}^{\mathrm{TiO}_{2}}$ 110 is not an abundant soil oxide $\left(10^{\text {th }}\right.$ in crustal abundance at $\sim 0.4 \%$ by weight $)$ (Perkins, 2002), its 111 importance is augmented by widespread industrial use and subsequent anthropogenic sources 112 (Kaegi et al., 2008; Nowack and Bucheli, 2007), including processed food (Weir et al., 2012). 
114 Some previous studies have investigated the interactions between $\mathrm{FQ}$ and $\mathrm{TiO}_{2}$ in aqueous

115 solutions. For example, sorption and removal of the FQ, ofloxacin, have been demonstrated (Van

116 Wieren et al. 2012). That study focused on isotherms at different $\mathrm{pH}$ and presented evidence

117 based on LC/MS data for the removal of OFL parent molecule from solution, as well as the

118 simultaneous generation of FQ degradation products, without detailed understanding of the

119 mechanisms. Other studies have shown the $\mathrm{TiO}_{2}$-enhanced photocatalytic degradation of $\mathrm{FQ}$

120 when exposed to UV radiation (Ohko et al., 2002; Calza et al., 2004; Doll and Frimmel, 2005;

121 An et al., 2010). One study (Paul et al., 2007) demonstrated that some FQ degrade in visible

122 light in the presence of $\mathrm{TiO}_{2}$. While these studies have provided important information on the 123 photochemical degradation of FQ in solution, little is known regarding the mechanisms and 124 modes of FQ sorption on $\mathrm{TiO}_{2}$, and whether $\mathrm{TiO}_{2}$ also catalyzes the degradation of FQ in the 125 dark. The goals of this study were to test whether or not $\mathrm{TiO}_{2}$ enhances degradation of FQ 126 without the input of light, and also to investigate FQ components in solution and the attendant 127 FQ components sorbed to the $\mathrm{TiO}_{2}$ surface, as the result of interaction in the dark.

\section{2. Methods}

\subsection{Materials}

131 The representative FQ drug used in this study was ofloxacin (OFL) (Sigma O8757, CAS 82419132 36-1; MW = 361.4), a synthetic antibiotic. OFL forms cationic, zwitterionic, and anionic species 133 in solution, depending on $\mathrm{pH}$ (Park et al., 2002). The structure of OFL and its speciation is 134 illustrated in Supplementary Material A1. 
$136 \mathrm{TiO}_{2}$ used in experiments was $25-\mathrm{nm}$ anatase with a nominal specific surface area of $200 \mathrm{~m}^{2} / \mathrm{g}$, 137 (Sigma 637254, CAS 1317-70-0), as provided by the manufacturer. This does not account for 138 agglomeration into larger aggregates upon suspension in solution (French et al., 2009; Tso et al., 139 2010). Particle size distribution measurements were performed in suspensions using a Brookhaven 90 140 Plus Instrument (B1-MAS). At pH 3.2, $\mathrm{TiO}_{2}$ occurs with an average particle size of $556(+/-4) \mathrm{nm}$, 141 as a bimodal distribution about 7\% (113 nm) and 93\% (644 nm). At pH 6.4, $\mathrm{TiO}_{2}$ occurs with an 142 average particle size of $1719(+/-109) \mathrm{nm}$, as a bimodal distribution about $28 \%(755 \mathrm{~nm})$ and $14372 \%(3315 \mathrm{~nm})$. This increase in particle size of one to two orders of magnitude for aggregates 144 in aqueous suspension is consistent with previous observations (Fang et al., 2009). The surface 145 charge of $\mathrm{TiO}_{2}$ nanoparticles in water is characterized by the point of zero charge (pzc). The pzc 146 is the $\mathrm{pH}$ below which the net surface charge of the oxide is positive (Drever, 1997). Zeta 147 potential measurements in this study (Brookhaven 90 Plus, B1-MAS) indicate a pzc between $\mathrm{pH}$ 148 5.06-5.41. (Supp A1).

\subsection{Protocol}

152 Twenty-one experiments were performed by mixing nanoparticle suspensions of different $\mathrm{pH}$ 153 with OFL solutions of known concentrations. $\mathrm{TiO}_{2}$ stock suspensions of 194 to $258 \mathrm{mg} / \mathrm{L}$ (mass

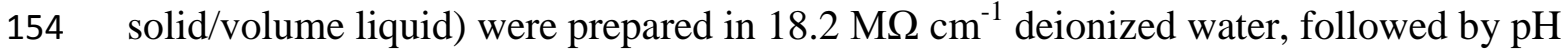
155 adjustment with dilute $\mathrm{NaOH}$ or $\mathrm{HCl}$. Stock OFL solutions were also prepared in deionized 156 water at concentrations ranging from $94-387 \mu \mathrm{M}$. The $\mathrm{pH}$ values of stock solutions of $\mathrm{TiO}_{2}$ 
157 suspensions and OFL solutions were measured directly. The $\mathrm{pH}$ of experimental mixes of $\mathrm{TiO}_{2}$ 158 and OFL were calculated based on dilutions. Experiments were performed at $\mathrm{pH} 3.2,3.3,6.1$, 159 6.4, 6.6, and 11.2, with the objective of experimenting at cationic, zwitterionic, and anionic 160 conditions for OFL. Experiments occurred by loading $1 \mathrm{~mL}$ of $\mathrm{TiO}_{2}$ stock suspension and $1 \mathrm{~mL}$ 161 of OFL solution into a $2 \mathrm{~mL}$ polypropylene centrifuge tube, followed by vigorous shaking for $1625 \mathrm{~min}$. Experimental concentrations for substrate and solute ranged from $97-129 \mathrm{mg} / \mathrm{L}$ and $47-$ $163194 \mu \mathrm{M}$, respectively. Tubes were paired with a control sample to which no $\mathrm{TiO}_{2}$ was added. 164 Tubes were then left undisturbed for 3-14 days, in the dark, at room temperature, during which 165 the nanoparticles settled out of suspension. Experiment duration (days) was selected to be on 166 the same time scale as common precipitation events and their subsequent infiltration rates, with 167 water movement from a loamy soil surface into the subsurface vadose zone (Dingman, 2002).

FQ concentrations used in this study were higher than most environmental detections, but not all.

Some surface waters have FQ concentrations 3-4 orders of magnitude lower (Kolpin et al., 2002), some wastewater treatment plant influent concentrations are 2 orders lower (Vieno et al., 2007), but some polluted surface waters and treatment plant effluent contain equivalent concentrations of FQ to those used in this study (Fick et al., 2009). Other workers have also used similar concentrations in FQ laboratory experiments (Figuero-Diva et al., 2010; Conkle et al., 2010) for reliable quantitative analysis and to model long-term loading in natural systems. $\mathrm{TiO}_{2}$ suspension concentrations were commensurate with OFL concentrations and were about the minimum level necessary for routine centrifugation, collection and spectroscopic analysis in this study. 
181 approximately $90-95 \%$ of the liquid. The decanted supernatant was divided into 3 separate

182 aliquots to be analyzed by fluorescence spectroscopic techniques. One aliquot was analyzed

183 directly, and a separate aliquot was filtered first through a sterile PALL Acrodisc ${ }^{\circ}$ PF 0.8/0.2

$184 \mu \mathrm{m}$ syringe filter with a hydrophilic polyethersulfone matrix before analysis. These filters

185 removed $\mathrm{TiO}_{2}$ and parent OFL species. This was demonstrated by trials of filtering and analysis

186 of control solutions, solutions with only OFL added or only $\mathrm{TiO}_{2}$ added. The remaining

187 supernatant suspension was centrifuged at 21,000 $\mathrm{g}(\mathrm{rcf})$ and the clarified liquid was analyzed

188 separately. The small amount of suspension remaining in the experiment sample tube was then

189 wicked off with a lab tissue, leaving a $\mathrm{TiO}_{2}$ substrate slurry, a portion of which was removed and

190 analyzed by Raman spectroscopic techniques. Following analysis of the nanoparticle substrate,

191 the remaining $\mathrm{TiO}_{2}$ nanoparticles were re-suspended in the tube with water lacking OFL and

$192 \mathrm{TiO}_{2}$. This sample was then vigorously mixed for $\sim 5$ minutes, followed by centrifugation and

193 decantation. Half of this supernatant was analyzed directly, and the other half filtered before

194 analysis. The remaining $\mathrm{TiO}_{2}$ substrate (post-re-suspension) was also analyzed by Raman

195 spectroscopy. Supernatants from the initial experiments were diluted by factors of 50 or $100 x$

196 and re-suspension liquids were diluted by $2 \mathrm{x}$ or $4 \mathrm{x}$ before analysis. Selected supernatants were

197 separated for LC/MS analysis and loaded into $2 \mathrm{~mL} \mathrm{HPLC}$ vials with a sterile syringe.

2.3 Instruments and Analysis

200

\subsubsection{Raman Spectroscopy}


201 Raman spectroscopy was used to investigate the sorption mechanisms of OFL onto $\mathrm{TiO}_{2}$ nanoparticle substrates. A small sample of substrate slurry was placed on a gold-coated slide and mounted on the microscope stage of the Raman instrument for analysis. Raman spectra were collected with a Renishaw micro-Raman system (Renishaw Inc., New Mills, UK) equipped with a $300 \mathrm{~mW}$ near-infrared (NIR) diode laser $(\lambda 785 \mathrm{~nm})$ and a CCD array detector. Signal to noise ratios were low when the sample was a suspension, but improved continuously as the material dried, changing from a wet slurry, to a slurry, to a damp paste. In this drying sequence, spectra collected from damp pastes were considered the optimal representations of sorbed OFL. OFL peaks were compared to spectra collected for OFL stock precipitated from aqueous solution (Supplementary Material A2). Assignments for prominent Raman shift peaks in the current study were primarily based on ATR-FTIR (Goyne et al., 2005) and FTIR-Raman (Sahoo et al., 212 2012) analysis of OFL, with some minor peak assignments referenced to other sources.

\subsubsection{Fluorescence Spectroscopy}

215 Both the filtered clear supernatant and the unfiltered suspension from experiments were analyzed 216 for parent OFL by fluorescence spectroscopy. Quantitative analysis measured the decrease in 217 OFL fluorescence due to the presence of $\mathrm{TiO}_{2}$. Data were collected with a HORIBA Scientific 218 Aqualog-800C spectrometer/fluorimeter instrument equipped with a $150 \mathrm{~W}$ continuous output 219 xenon lamp and CCD detector. Signals were corrected for inner-filter effects and $1^{\text {st }}$ order 220 Rayleigh scattering with AquaLog ${ }^{\circledR} 3.6$ software, and post-processed with Origin®. Excitation 221 wavelength $\left(\lambda_{\mathrm{ex}}\right)$ of $293 \mathrm{~nm}$ was used to document fluorescence at $500.7 \mathrm{~nm}$ emission 222 wavelength $\left(\lambda_{\mathrm{em}}\right)$ for all samples. 


\section{$224 \quad 2.3 .3 \mathrm{LC} / \mathrm{MS}$}

225 Selected supernatants were also analyzed by liquid chromatography/mass spectroscopy (LC/MS)

226 to identify OFL degradation products. Product $\mathrm{m} / \mathrm{z}$ values were determined by a single

227 quadrupole mass selective detector (Agilent 1100 LC/MSD SL). Sample injections of $20 \mu \mathrm{L}$

228 were separated on Kinetex EVO 150 C-18 column $(100$ x 4.6 mm, $5 \mu$ m diameter particle size $)$

229 at a flow rate of $0.8 \mathrm{~mL} / \mathrm{min}$ using an isocratic mobile phase of $5 \%$ acetonitrile $/ 95 \%$ water with

$2300.3 \% \mathrm{v} / \mathrm{v}$ formic acid. UV absorbance was monitored by diode array detection at 242, 254, 287 ,

231293 , and $329 \mathrm{~nm}$ wavelength. Analytes that did not absorb at the selected wavelengths were

232 distinguishable at different retention times on the total ion count (TIC) spectra. The MSD was

233 operated in the atmospheric pressure ionization - electrospray mode with positive ion detection,

234 and a mass fragmentor voltage of $40 \mathrm{~V}$. Compounds were identified in both scan mode (100-800

$235 \mathrm{~m} / \mathrm{z}$ ) and selected ion mode (SIM) with 24 separate $\mathrm{m} / \mathrm{z}$ intervals $( \pm 0.1)$ ranging from 119.1-

236119.2 to $363.2 \mathrm{~m} / \mathrm{z}$.

237

238 3. Results

239

2403.1 Sorption of $O F L$

241 Fluorescence spectroscopic analysis of samples of OFL mixed with a $\mathrm{TiO}_{2}$ suspension at $\mathrm{pH} 6.1$

242 indicates a nominal partitioning of $1071 \mathrm{~L} / \mathrm{kg}$, or $5.4 \times 10^{-3} \mathrm{~L} / \mathrm{m}^{2}$. This value is consistent with

243 previously-published results (1288 \pm 217$) \mathrm{L} / \mathrm{kg}$ (Van Wieren et al. 2012) from an isotherm at

244 nearly the same pH (6 vs. 6.1). Example spectra are illustrated in Supplementary Material A3. 


\subsection{OFL on $\mathrm{TiO}_{2}-\mathrm{pH}$ Comparison}

Figure 1 shows representative Raman spectra of $\mathrm{OFL}$ on $\mathrm{TiO}_{2}$ collected from damp pastes from experiments performed at $\mathrm{pH} 3.3,6.4$, and 11.2. These represent conditions where OFL is mostly cationic, zwitterionic, and anionic, respectively. A spectrum from OFL stock precipitated at pH 6.6 (Supp. A2) is shown for comparison. While the overall appearance of the spectra is similar, some distinct differences are evident. Several peaks are blue-shifted for OFL on $\mathrm{TiO}_{2}$, compared to the stock OFL precipitate. These are peaks assigned to $\mathrm{C}=\mathrm{C}$ stretching $\left(1545 \mathrm{~cm}^{-1}\right)$ in the quinolone moiety, plus $\mathrm{C}-\mathrm{H}_{3}$ stretching $\left(1444 \mathrm{~cm}^{-1}\right)$ and $\mathrm{C}-\mathrm{O}-\mathrm{C}$ ether stretching $\left(1042 \mathrm{~cm}^{-}\right.$ ${ }^{1}$ ) in the benzoxazine moiety. These shifts are relatively independent of $\mathrm{pH}$. A red-shift of the $\mathrm{C}-\mathrm{C}$ stretching/C-H deformation peak $\left(1142 \mathrm{~cm}^{-1}\right)$ is also observable and is slightly greater at $\mathrm{pH}$ 6.4. The pH 6.4 spectrum also shows the emergence of a peak at $1299 \mathrm{~cm}^{-1}$, probably attributable to $\mathrm{C}-\mathrm{H}_{2} / \mathrm{C}-\mathrm{H}_{3}$ twisting mode (NyQuist, 2001) of the benzoxazine core component. The peak assigned to symmetric stretching of $\mathrm{COO}^{-}\left(1340 \mathrm{~cm}^{-1}\right)$ is present in all samples.

\subsection{Desorption of OFL}

Figure 2 compares the Raman spectrum of $\mathrm{OFL}$ on $\mathrm{TiO}_{2}$ substrate after an initial mixing experiment with a spectrum of the same substrate after re-suspension in OFL-free solution (rinsing) and subsequent decantation of the supernatant. Two distinct peaks are present in the spectrum of OFL attached after initial mixing. These are a $\mathrm{C}=\mathrm{O}$ stretching (pyridine)/ $\mathrm{NH}^{+}$ deformation (piperazinyl) peak at $1626 \mathrm{~cm}^{-1}$ and the peak assigned to the protonation and $\mathrm{CH}_{2} / \mathrm{CH}_{3}$ deformation of the piperazinyl ring at $1401 \mathrm{~cm}^{-1}$. Three smaller peaks are also present after initial mixing, the $\mathrm{C}=\mathrm{C}$ stretching (quinolone) peak at $1559 \mathrm{~cm}^{-1}$, a $\mathrm{C}-\mathrm{H}_{3}$ stretching peak from benzoxazine at $1454 \mathrm{~cm}^{-1}$, and a peak assigned to the symmetric stretching of the 
269 carboxylate anion at $1342 \mathrm{~cm}^{-1}$. After re-suspension/rinsing of the substrate, the spectrum shows

270 a diminishing of the pyridine and piperazinyl components and an increase of the $\mathrm{CH}_{3}$

271 components on the surface. The carboxylate anion peak is also relatively less distinct after re-

272 suspension. Those parts of the OFL molecule attributable to the diminished peaks must have

273 been removed/desorbed from the substrate during re-suspension, while $\mathrm{CH}_{3}$ groups remained

274 attached to the surface. Based on florescence spectroscopic analysis of the rinsate, a maximum of

$275 \sim 18 \%$ of the sorbed OFL could be removed from the $\mathrm{TiO}_{2}$ substrate.

277

278

\subsection{OFL Components in Solution}

Supernatants from $\mathrm{OFL}_{-} \mathrm{TiO}_{2}$ experiments were analyzed by LC/MS techniques to identify OFL degradation products in solution. Figure 3 shows mass spectra from the liquids attendant to the substrates analyzed in Figure 2. Figure $3 \mathrm{a}$ is a spectrum of the centrifuged supernatant from the experiment of $55 \mu \mathrm{M}$ OFL and $129 \mathrm{mg} / \mathrm{L}$ of $\mathrm{TiO}_{2}$, at $\mathrm{pH}$ 6.1, after 139 hours (about 6 days) of interaction. This liquid was present with the substrate analyzed by Raman spectroscopy, the spectrum of which is indicated by a dashed line in Figure 2. In addition to OFL parent $(\mathrm{m} / \mathrm{z}=$ 362.2, not shown), OFL breakdown products are present. These include quinolone core components which are missing the piperazinyl group and are also de-carboxylated and hyrdroxylated and/or de-methylated. An m/z value corresponding to a succinylated piperazinyl group is also present. Figures $3 b-d$ are spectra from the rinsate after re-suspension of the same substrate attendant to the liquid of Figure 3a. These mass spectra correspond to the Raman spectrum of the desorbed substrate indicated by a solid line in Figure 2. OFL breakdown products desorbed from the $\mathrm{TiO}_{2}$ substrate include masses assignable to de-methylated quinolone cores and ethyl-1 piperazine carboxylate (Figure 3b), de-carboxylated/hydroxalted parent (Figure 
292 3c), and intact OFL parent molecule plus parent with a de-methylated piperazinyl ring (Figure $2933 d)$

\section{4. Discussion}

296 Raman spectra collected in this study (Figs. 1 and 2) indicate that the dominant OFL moieties

297 involved in the $\mathrm{TiO}_{2}$ surface interactions are functional groups of both the benzoxazine-

298 quinolone core, and the protonated $\mathrm{N}_{4}$ of the piperazinyl group. Indirect support for

299 benzoxazine-quinolone core activity can be seen in the spectra at low and high pH (Fig. 1). At

$300 \mathrm{pH} 3.3$, OFL is cationic and the $\mathrm{TiO}_{2}$ surface is also positively charged (Supp. A1) so

301 electrostatic repulsion exists between the substrate surface and the ionization sites of OFL. The

302 opposite repulsive effect exists at $\mathrm{pH} 11.2$, where OFL is anionic and the $\mathrm{TiO}_{2}$ surface is

303 negatively charged. Therefore at low and high $\mathrm{pH}$, involvement of the piperazinyl and

304 carboxylic acid groups would not be expected. However, the ketone group of the quinolone

305 and/or the methyl group of the benzoxazine are candidates for surface interaction. Ketone

306 complexation has been observed for OFL- $\mathrm{Al}_{2} \mathrm{O}_{3}$ interactions (Goyne et al., 2005), ciprofloxacin

307 complexation to hydrous iron oxide (Gu and Karthikeyan, 2005), and other FQ adsorption to

$308 \mathrm{TiO}_{2}$ (Paul et al., 2007). De-alkylated transformation products of several FQ, including OFL,

309 have been reported (Zhang and Huang, 2005; 2007), suggesting methyl group adsorption, and are

310 consistent with Raman observations in this study.

312 Spectra from near $\mathrm{pH} 6$ are important because here OFL is cationic and zwitterionic and the $\mathrm{TiO}_{2}$ 313 surface is negatively charged (Supp. A1). A comparison (Fig. 2) of what OFL components 314 attach during the initial mixing versus what remains after desorption directly indicates the role of 
315 the benzoxazine-quinolone core functional groups and the protonated piperazinyl at the substrate 316 surface. This evidence is the decrease of the $\mathrm{C}=\mathrm{O} / \mathrm{NH}^{+}$peak at $1626 \mathrm{~cm}^{-1}$, and the $\mathrm{NH}^{+} / \mathrm{CH}_{2} / \mathrm{CH}_{3}$

317 peak at $1400 \mathrm{~cm}^{-1}$. Others (An et al., 2010) have proposed that the first step in $\mathrm{TiO}_{2}$-catalyzed 318 photodegradation of FQ is partial or complete elimination of the piperazinyl ring, followed by 319 hydroxylation reactions with the parent quinolone core, as part of an adsorption/desorption 320 process. If elimination of the piperazinyl ring and hydroxylation of the quinolone is caused by 321

LC/MS results complement the Raman spectra in terms of surface interactions and OFL degradation. OFL degradation products remaining in solution after mixing (Fig. 3a) lack the piperazinyl ring, are de-carboxylated, and lack the quinolone ketone group. Desorbed degradation products (Figs. 3b-d) include de-methylated moieties and carboxylated piperazinyl rings. Previous LC/MS analysis of degradation products at these conditions (Van Wieren et al., 
339 This is consistent with the current interpretation.

340 Succinylation of the piperazinyl ring, desorbed from the substrate, has been reported previously 341 (Terzic et al. 2011), and is recognized as an important biotransformation product of FQ in the 342 overall study of pharmaceuticals in aquatic environments (Michael et al., 2014).

\section{Conclusions}

Experiments were performed to investigate surface interactions and OFL degradation in aqueous $\mathrm{TiO}_{2}$ suspensions in the dark. OFL components sorbed at the substrate surface were detected by Raman spectroscopy, and OFL species were detected in the attendant solutions by LC/MS.

Raman spectra indicate sorption occurs via the $\mathrm{C}=\mathrm{O}$ (ketone) and $\mathrm{CH}_{3}$ group of the benzoxazinequinolone core, and the $\mathrm{NH}^{+}$of the piperazinyl ring. Raman spectra also show that benzoxazinequinolone ketone groups and piperazinyl groups are most readily removed/desorbed from the surface. Complementary information from analysis of the attendant supernatants indicates the presence of quinolone and piperazinyl groups in solution. Sorption breaks the compound into piperazinyl and quinolone groups which attach to the substrate surface. Decarboxylated and hydroxylated quinolone moieties do not attach to $\mathrm{TiO}_{2}$ and stay in solution. Altered piperazinyl 360 occurred in the dark during experiments on the order of 100 hours in length. UV-mediated 
2

3

4

8

361 degradation occurs on the order of 10s of minutes to 1 hour (Paul et al., 2007; An et al., 2010).

More study is needed to understand the kinetics and sequence of $\mathrm{FQ}^{-\mathrm{TiO}_{2}}$ interactions under

363 low-light conditions.

364

365

366

367 This research was sponsored in part by the Hope College Department of Geological \&

368 Environmental Sciences and the GLCA-ACM Oak Ridge Science Semester Program, and by the

369 Office of Biological and Environmental Research, Office of Science, US Department of Energy

370 (DOE). Oak Ridge National Laboratory is managed by UT-Battelle LLC for the DOE under

371 contract DE-AC05-00OR22725. Thanks to Xiangping Yin and Xia Lu for their assistance with
373

374 Appendix A. Supplementary Materials

375 Supplementary figures to this article (A1, A2, and A3) can be found online.
376

377

378

379

380

381

382

383 


\section{References}

386 An, T., Yang, H., Song, W., Li, G., Luo, H., Cooper, W.J., 2010. Mechanistic considerations for

387 the advanced oxidation treatment of fluoroquinolone pharmaceutical compounds using $\mathrm{TiO}_{2}$

388 heterogeneous catalysis. J. Physical Chemistry A 114, 2569-2575.

390 Barnes, K.K., Kolpin, D.W., Furlong, E.T., Zaugg, S.D., Meyer, M.T., Barber, L.B., 2008. A

391 national reconnaissance of pharmaceuticals and other organic wastewater contaminants in the

392 United States - I) Groundwater. Science of the Total Environment 402, 192-200.

Calza, P., Medana, C., Pazzi, M., Baiocchi, C., Pelizzetti, E., 2004. Photocatalytic

397 (CDC) Centers for Disease Control, Antibiotic Resistance Threats in the United States, 2013

399 Chander, Y., Kumar, K., Goyal, S.M., Gupta, S.C., 2005. Antibacterial activity of soil-bound 400 antibiotics. Journal of Environmental Quality 34, 1952-1957.

402 Chorover, J., Amistadi, M.K., 2001. Reaction of forest floor organic matter at goethite, birnessite 403 and smectite surfaces. Geochimica et Cosmochimica Acta 65, 95-109. 
2

3

Conkle, J.L., Lattao, C., White, J.R., Cook, R.L., 2010. Competitive sorption and desorption behavior for three fluoroquinolone antibiotics in wastewater treatment wetland soil.

Chemosphere 80, 1353-1359.

409 Davies, J., Davies, D., 2010. Origins and evolution of antibiotic resistance. Microbiology and 410 Molecular Biology Review 74, 417-33.

412 Dingman, S.L., 2002. Physical Hydrology, second ed. Prentice Hall, New Jersey.

414 Doll, T.E., Frimmel, F.H., 2005. Photocatalytic degradation of carbamezapine, clofibric acid and 415 iomeprol with P25 and Hornbikat UV100 in the presence of natural organic matter (NOM) and 416 other organic water constituents. Water Res. 39, 403-411.

418 Drever, J.I., 1997. The Geochemistry of Natural Waters: Surface and Groundwater 419 Environments, third ed. Prentice Hall, New Jersey.

421 Fang, J., Shan, X., Wen, B., Lin, J., Owens, G., 2009. Stability of titania nanoparticles in soil 422 suspensions and transport in saturated homogeneous soil columns. Environmental Pollution 157, 423 1101-1109.

425 Fick, J., Söderström, H., Lindberg, R.H., Phan, C., Tyksklind, M., Larsson, D.G.J., 2009.

426 Contamination of surface ground, and drinking water from pharmaceutical production.

427 Environmental Toxicology and Chemistry 28, 2522-2527. 
429 Figuero-Diva, R. A., Vasudevan, D., MacKay, A.A., 2010. Trends in soil sorption coefficients 430 within common antimicrobial families. Chemopshere 79, 786-793.

432 French, R.A., Jacobson, A.R., Kim, B., Isley, S.L., Penn, R.L., Baveye, P.C., 2009. Influence of 433 ionic strength, $\mathrm{pH}$, and cation valence on aggregation kinetics of titanium dioxide nanoparticles. 434 Environmental Science and Technology 43, 1354-1359.

Giger, W., Alder, A.C., Golet, E.M., Kohler, H.P.E., McArdell, C.S., Molnar, E., Siegrist, H., 437 Suter, M.J.F., 2003. Occurrence and fate of antibiotics as trace contaminants in wastewaters, 438 sewage sludges, and surface waters. Chimia 57, 485-491.

440 Goyne, K.W., Chorover, J., Kubicki, J.D., Zimmerman, A.R., Brantley, S.L., 2005. Sorption of 441 the antibiotic ofloxacin to mesoporous and nonporous alumina and silica. Journal of Colloid 442 and Interface Science 283, 160-170.

$444 \mathrm{Gu}, \mathrm{C} .$, Karthikeyan, K.G., 2005. Sorption of the antimicrobial ciprofloxacin to aluminum and 445 iron hydrous oxides. Environ. Sci. Technol. 39, 9166-9173.

446

447 Kaegi, R., Ulrich, A., Sinnet, B., Vonbank, R., Wichser, A., Zuleeg, S., Simmler, H., Brunner, 448 S., Vonmont, H., Burkhardt, M., Boller, M., 2008. Synthetic $\mathrm{TiO}_{2}$ nanoparticle emission from 449 exterior facades into the aquatic environment. Environ. Pollut. 156, 233-239. 
Kim, S., Jensen, J.N., Aga, D.S., Weber, A.S., 2007. Tetracycline as a selector for resistant

bacteria in activated sludge. Chemosphere 66, 1643-1651.

Kolpin D.W., Furlong, E.T., Meyer, M.T., Thurman, E.M., Zaugg, S.D., Barber, L.B., Buxton, 455 H.T., 2002. Pharmaceuticals, hormones, and other organic wastewater contaminants in US 456 streams, 1999-2000: A national reconnaissance. Environ. Sci. \& Tech. 36, 1202-1211.

458 Kümmerer, K., 2009a. Antibiotics in the aquatic environment - A review - Part I. Chemosphere $459 \quad 75,417-434$

464 Maia, A.S., Ribeiro, A.R., Amorim, C.L., Barreiro, J.C., Cass, Q.B., Castro, P.M.L., Tiritan, 465 M.E., 2014. Degradation of fluoroquinolones antibiotics and identification of 466 metabolites/transformation products by liquid chromatography-tandem mass spectrometry. 467 Journal of Chromatography A 1333, 87-98.

469 Michael, I., Vasquez, M.I., Hapeshi, E., Haddad, T., Baginska, E., Kümmerer, K., Fatta470 Kassinos, D., 2014. Metabolites and transformation products of pharmaceuticals in the aquatic 471 environment as contaminats of emerging concern. In Lambropoulou, D.A. and Nollet, L.M.L., 472 eds., Transformation Products of Emerging Contaminants in the Environment: Processes, 473 Occurrence, Effects and Risks, $1^{\text {st }}$ edt., Wiley, pgs. 413-457. 
2

3

474

8

478

492

Nakata, H., Kannan, K., Jones, P.D., Giesy, J.P., (2005). Determination of fluoroquinolones antibiotics in wastewater effluents by liquid chromatography-mass spectrometry and fluorescene detection. Chemosphere 58, 759-766.

479 Nowack, B., Bucheli, T.D., 2007. Occurrence, behavior and effects of nanoparticles in the 480 environment. Environ. Pollut. 150, 5-22.

482 Normark, B.H., Normark, S., 2002. Evolution and spread of antibiotic resistance. Journal of 483 Internal Medicine 252, 91-106.

485 NyQuist, R.A., 2001. Interpreting infrared, Raman, and nuclear 486 magnetic resonance spectra, v. 1, Variables in data interpretation of infrared and Raman spectra, 487 Academic Press, San Diego, 477 pp.

489 Ohko, Y., Iuchi, K.I., Niwa, C., Tatsuma, T., Nakashima, T., Iguchi, T., Kubota, Y., Fujishima, 490 A., 2002. 17ß-estradiol degradation by $\mathrm{TiO}_{2}$ photocatalysis as a means of reducing estrogenic 491 activity. Environ. Sci. Technol. 36, 4175-4181.

493 Park, H-R., Kim, T.A., Bark, K-M., 2002. Physicochemical properties of quinolone antibiotics 494 in various environments. European Journal of Medicinal Chemistry 37, 443-460. 
Paul, T., Miller, P.L., Strathmann, T.J., 2007. Visible-light-mediated $\mathrm{TiO}_{2}$ photocatalysis of

497 fluoroquinolone antibacterial agents. Environ. Sci. Technol. 41, 4720-4727.

499 Perkins, D., 2002. Mineralogy, second ed. Prentice Hall, New Jersey.

502 Bioanalytical Chemistry 387, 1287-1299.

516 Van Wieren, E.M., Seymour, M.D., Peterson, J.W., 2012. Interaction of the fluoroquinolone 517 antibiotic, ofloxacin, with titanium dioxide nanoparticles in water: adsorption and breakdown. 518 Science of the Total Environment 441, 1-9. 
Vieno, N., Tuhkanen, T., Kronberg, L., 2007. Elimination of pharmaceuticals in sewage

521 treatment plants in Finland. Water Research 41, 1001-1012.

523 Weir, A., Westerhoff, P., Fabricus, L., Hristovski, K., von Goetz, N., 2012. Titanium dioxide 524 nanoparticles in food and personal care products. Environmental Science and Technology 46, $525 \quad 2242-2250$.

526

527 Yu, D.J., Yi, X.L., Ma, Y.F., Yin, B., Zhuo, H.L., Li, J., Huang, Y.F., 2009. Effects of

528 administration mode of antibiotics on antibiotic resistance of Enterococcus faecalis in aquatic 529 ecosystems. Chemosphere 76, 915-920.

530

532 and structurally related amines with goethite. Chemosphere 66, 1502-1512.

533

534 Zhang, H., Huang, C.H., 2005. Oxidative transformation of fluoroquinolone antibacterial agents 535 and structurally related amines by manganese oxide. Environ. Sci. Technol. 39, 4474-4483.

537 Zuccato, E., Calamari, D., Natangelo, M., Fanelli, R., 2000. Presence of therapeutic drugs in the 538 environment. The Lancet 355, $1789-1790$. 
2

3

4
5 $540 \quad$ FIGURE CAPTIONS

6

7541

8

9 10

11

12

13

14

15 547 solution.

Fig. 2. Raman spectra of OFL components attached to $\mathrm{TiO}_{2}$ substrate after initial mixing $(\mathrm{pH}=$ 546 6.1) compared to OFL components remaining after re-suspension/desorption in OFL-free

548

549 Fig. 3. Mass spectra of OFL and OFL degradation products in solution: (a) After initial mixing 550 with $\mathrm{TiO}_{2}$ suspension, parent OFL (m/z =362.2) not shown; (b-d) After re-suspension/desorption 551 of $\mathrm{TiO}_{2}$ substrate. $\mathrm{RT}=$ retention time. 


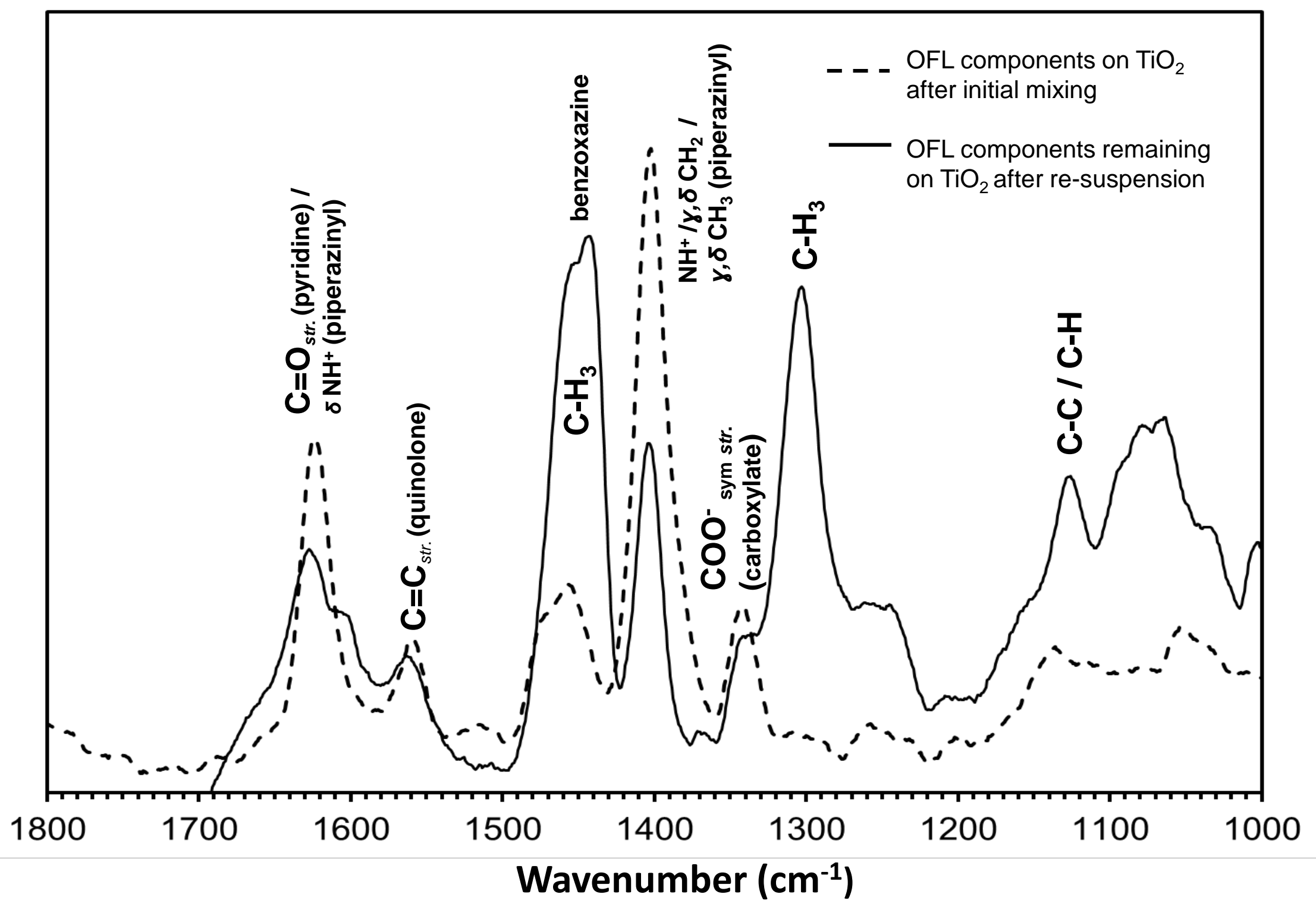


(a)
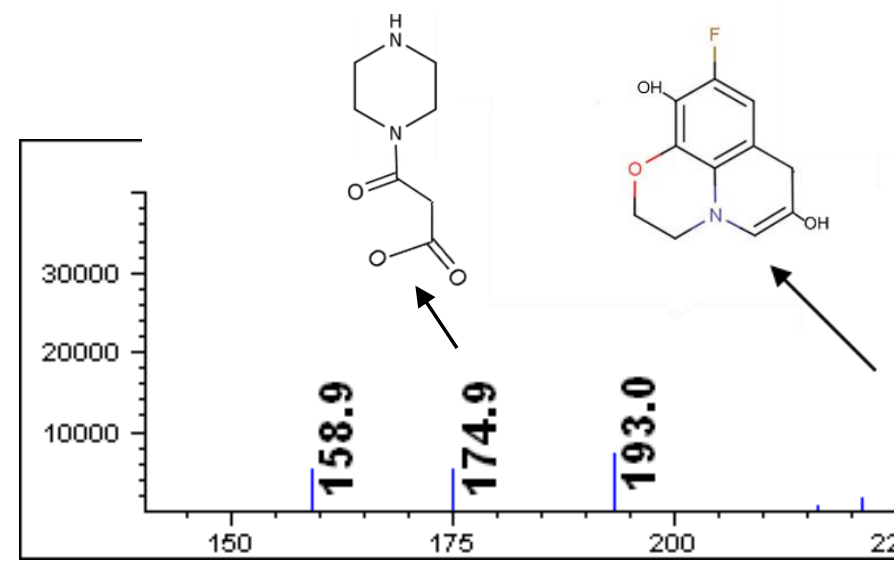
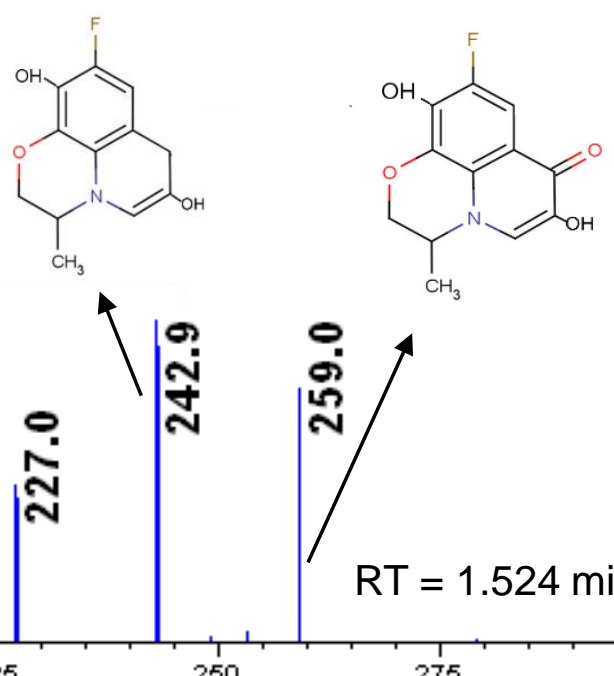

250

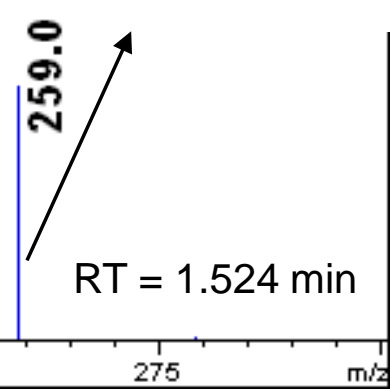

(b)

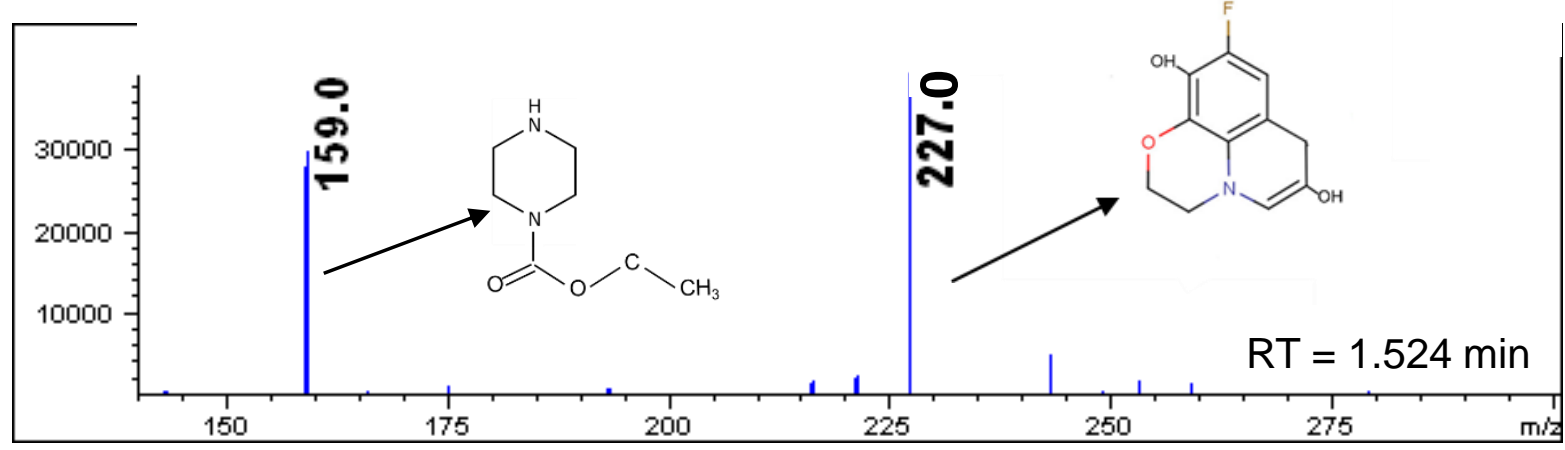

(c)

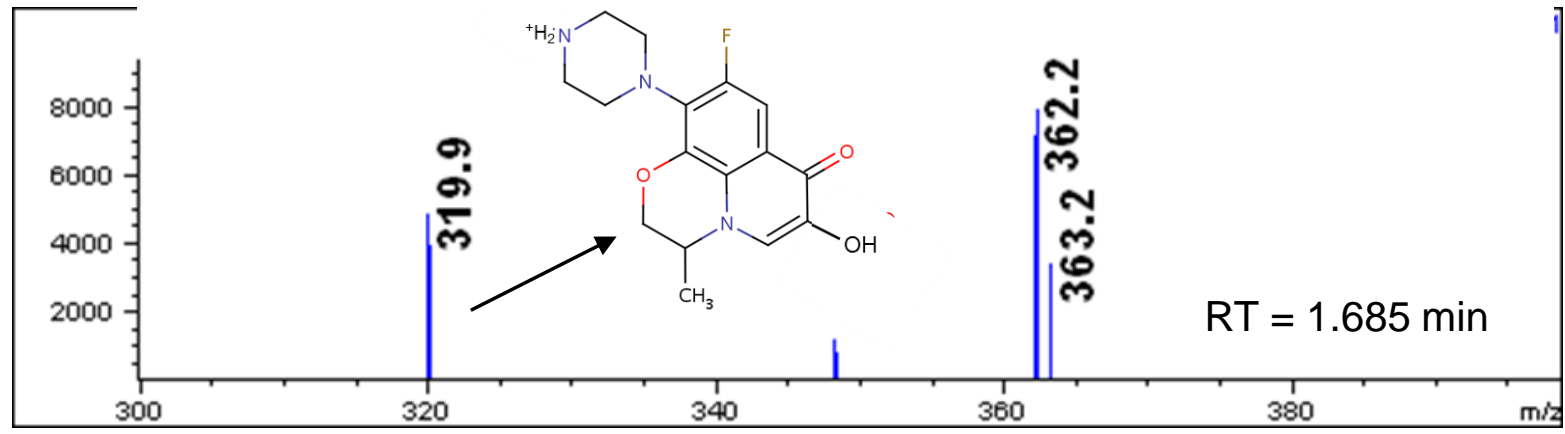

(d)

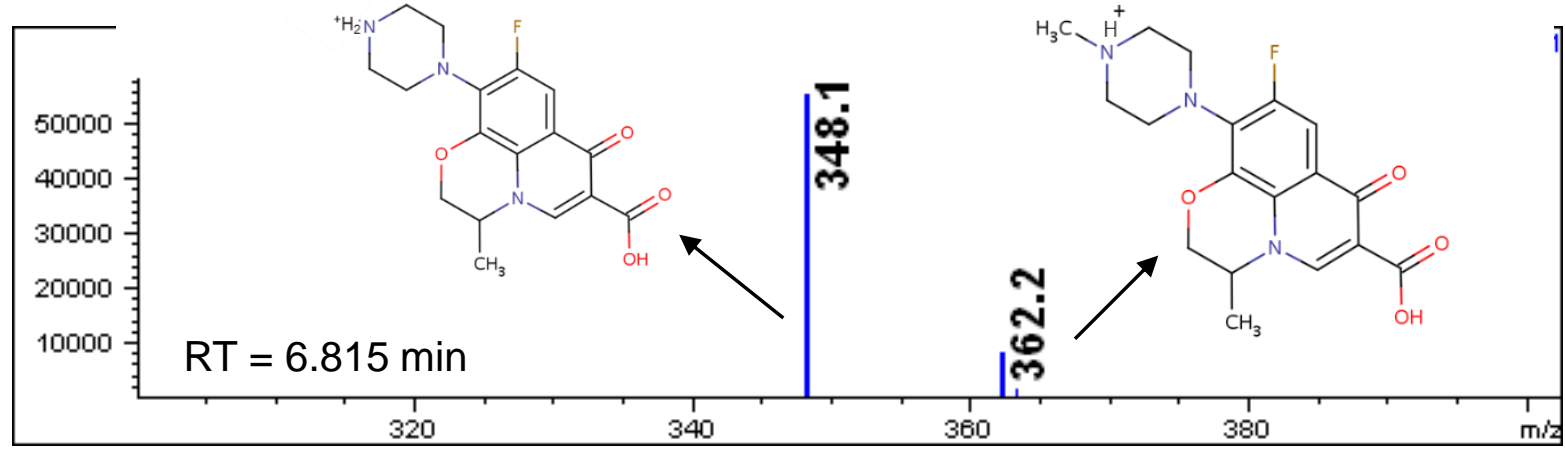

$\mathrm{m} / \mathrm{z}$ 